\title{
Ascensão capilar de água em substratos de coco e de pinus
}

\author{
Carlos Vinicius Garcia Barreto $\left({ }^{1 *}\right)$; Roberto Testezlaf $\left({ }^{2}\right)$; Conan Ayade Salvador $\left({ }^{3}\right)$ \\ (1) INPI, Rua São Bento, 1, 20090-010 Rio de Janeiro (RJ), Brasil. \\ (2) UNICAMP, Faculdade de Engenharia Agrícola, Av. Candido Rondon, 501, 13083-875 Campinas (SP), Brasil. \\ (3) ESALQ/USP, Escola Superior de Agricultura “Luiz de Queiroz”, Av. Pádua Dias, 11, 13418-900 Piracicaba (SP), Brasil. \\ (*) Autor correspondente: carbar001@gmail.com
}

Recebido: 27/jan./2012; Aceito: 10/jul./2012

\begin{abstract}
Resumo
O uso da irrigação por capilaridade na produção de mudas em viveiros pode trazer vantagens ao uso de água e sua utilização adequada requer o conhecimento da capacidade de ascensão de água no meio de crescimento das raízes, atributo pouco estudado. Para avaliar esta condição fundamental, este trabalho tem como objetivo avaliar a ascensão de água em substratos comerciais de coco e pinus, em dois padrões de tamanho de partículas e em duas condições de umidade, para indicar aquele que possua as melhores características físicas para aplicação na irrigação por capilaridade. Utilizou-se o método de ascensão capilar, com colunas desmontáveis de anéis preenchidas com substratos, avaliando-se os seguintes tempos de contato do fundo da coluna com a lâmina de água: 0,25, 0,5, 1, 2, 4, 8, 16 e 24 horas, com 10 repetições por tempo testado. Pelos resultados, observou-se que a maior ascensão capilar acumulada em 24 horas de ensaio foi obtida para os substratos de textura fina de coco e de pinus. Além disso, a hidrofobia do substrato de coco seco recomenda que as irrigações nesse material devem ter frequências maiores que substratos de pinus, evitando seu secamento. O substrato de pinus, por não apresentar esse comportamento, deve ter turnos de rega mais espaçados, principalmente sob textura fina. Devido à sua maior retenção de água e capacidade de elevação de água quando umedecido, o substrato fino de coco é mais adequado à irrigação por capilaridade em recipientes como tubetes.
\end{abstract}

Palavras-chave: irrigação por capilaridade, produção de mudas, viveiros, física de substratos.

\section{Capillary water rise in coconut and pine bark substrates}

\section{Abstract}

The capillary irrigation in nursery production could give advantages in water use and its correct application demands knowledge about capillary water rise through root growth media, an attribute poorly studied. This research had as objective to evaluate water capillary rise in commercial pine and coconut substrates for two particle size distributions and two moisture conditions, to indicate the substrate with the best physical characteristics for capillary irrigation. The capillary rise determination method was applied on disassembled rings column filled with substrates, evaluating the following contact durations of the column bottom with water surface: $0.25,0.5,1,2,4,8,16$ and 24 hours, with 10 repetitions per time. The results showed that the fine pine and coconut substrates had the higher water rise during the 24 hours test. Moreover, the hydrophobic state presented by coconut substrate indicated high irrigation frequencies for this material in comparison to pine substrate, avoiding that drying conditions become irreversible. The pine bark substrate did not show this problem, needing longer irrigation intervals, especially with the fine texture one. Due to the greater water holding and water rise capacity for wet conditions, the fine coconut substrate showed more suitable for capillary irrigation in small recipients.

Key words: capillarity irrigation, seedlings production, nurseries, substrate physics.

\section{INTRODUÇÃO}

Um líquido com determinada tensão superficial em contato com uma parede de um recipiente promove os primeiros fenômenos capilares (Libardi, 2005). Segundo esse autor, a capilaridade também está presente na retenção de água de solos devido aos microporos, determinando nas camadas superficiais do solo um fluxo ascensional de água devido aos processos de evapotranspiração (Berkowitz et al., 2004). No entanto, a atuação da capilaridade é dependente da interação de outros fatores, tais como das características das partículas de solo ao molhamento (Goebel et al., 2002) e seu envolvimento com produtos hidrofóbicos que geram maiores de ângulo de contato na interface do colóide com a água (BAChmann et al., 2000). Adicionalmente, Berkowitz et al. (2004) afirmam que a relação 
entre partículas e seu potencial mátrico são importantes para ocorrência da ascensão capilar nas camadas acima da franja capilar.

As premissas válidas em física de solos são parcialmente aplicáveis para substratos, e CARON e ELRICK (2005) constataram que a condutividade hidráulica para substratos varia com o potencial de água no seu interior e que, com valores de umidade próximos à saturação, ocorre acentuada elevaçáo da condutividade hidráulica. CARON et al. (2005) afirmam que o uso de substratos com partículas de granulometrias finas também contribui para este fenômeno, pois, segundo Michel et al. (2008), a facilidade ao molhamento deve ser atribuída principalmente ao tamanho ou granulometria das partículas. No entanto, quaisquer alteraçóes no diâmetro dos poros advindos de histerese dificultam os processos de molhamento, ao passo em que em paredes de poros pode haver ainda hidrofobia (Blok e Wever, 2008). Segundo estes autores, ainda remanescem indefiniçóes acerca de hidrofobia e dificuldades de molhamento em substratos.

Processos como estes são importantes, pois afetam a eficiência de irrigação, que pode limitar o desenvolvimento de plantas cultivadas por capilaridade (CARON e Elrick, 2008). Segundo Bilderback (2001), esse tipo de irrigação vem sendo adotado por produtores de olerícolas que empregam substratos, devido às suas vantagens, como alta eficiência de irrigação, a possibilidade do uso de nutrientes e de aporte de equipamentos e energia para sua operação com nível tecnológico simplificado, o que determina redução nos custos de produção (CHANSEETIS et al., 2001). Além disso, sistemas de irrigação por capilaridade possibilitam a reutilização da água com fertilizantes solubilizados, que quando incorretamente dispostos sobre o solo geram contaminação de recursos hídricos (Bilderback, 2001; Toshiaki et al., 2004).

As características dos sistemas de irrigação por capilaridade se sobressaem sobre sistemas de irrigação por aspersão, principalmente quando irrigam plantas acondicionadas em pequenos recipientes que aplicam água em toda a superfície, incluindo a área entre contêineres, o que determina baixas eficiências de aplicação (Yeager, 1995; Bilderback, 2001). Dessa forma, as perdas de água nesses sistemas são diretamente proporcionais às áreas cobertas pelas bordas dos recipientes e pela área de suporte da bandeja. Apesar dos conhecimentos existentes sobre a irrigação por capilaridade, faltam métodos de ensaios e informaçôes de segurança ao agricultor que atestem a real capacidade de ascensão vertical da frente de molhamento no substrato.

Neste contexto, o objetivo deste trabalho foi avaliar o processo de ascensão de água em dois tipos de substratos comerciais, com dois padrôes de tamanho médio de partículas e sob duas condiçóes de umidade dos substratos, buscando determinar qual foi o substrato de melhor desempenho e analisando o efeito das suas características físicas para aplicação na irrigação por capilaridade.

\section{MATERIAL E MÉTODOS}

Nos experimentos, avaliaram-se substratos de coco e de pinus para dois padróes de granulometria de partículas: partículas finas e grosseiras em duas condiçôes de umidade inicial do material (Tabela 1).

Para se avaliar o efeito da umidade presente no substrato e na sua capacidade em desenvolver a ascensão capilar, avaliaram-se esses meios de crescimento para duas condiçóes de umidade: substrato com umidade de comercialização e substrato seco ao ar. $\mathrm{O}$ uso de substratos sob esta última condição de umidade tinha o objetivo de fazer indicaçóes sob segurança do meio de crescimento e, tornar-se um padrão de análise física de substratos. A técnica adotada para esse trabalho derivou-se do método desenvolvido por Goebel et al. (2002) na determinação da ascensão capilar de água em solos. A principal adaptação foi a utilização de cilindros construídos a partir de tubos de PVC DN 25, com $10 \mathrm{~cm}$ de altura útil segmentados em anéis de $2 \mathrm{~cm}$, onde as amostras de substrato foram dispostas. Os anéis cilíndricos foram conectados em número de 5 anéis, todos com 2 centímetros de altura, exceto o primeiro que possuía $3 \mathrm{~mm}$ a mais que os demais, para permitir o contato com a água na formação de zona de saturação (Figura 1). A capacidade útil de cada cilindro era de $60,25 \mathrm{~cm}^{3}$, com $12,05 \mathrm{~cm}^{3}$ para cada anel, inclusive para o primeiro, pois o volume adicional de $1,8 \mathrm{~cm}^{3}$ de volume decorrentes de sua maior altura, não foi amostrado. Na parte inferior deste anel foi fixado um tecido, utilizando-se um elástico para

Tabela 1. Distribuição percentual (\%) do tamanho de partículas para os substratos: fino de pinus (PF), grosseiro de pinus (PG), fino de coco com componentes granulares $(\mathrm{CF}-\mathrm{G})$ e fibrosos $(\mathrm{CF}-\mathrm{F})$ e grosseiro de coco de componentes granulares $(\mathrm{CG}-\mathrm{G})$ e fibrosos $(\mathrm{CG}-\mathrm{F})$

\begin{tabular}{|c|c|c|c|c|c|c|c|}
\hline \multirow{2}{*}{ Substrato } & \multicolumn{7}{|c|}{ Peneira } \\
\hline & $<0,25$ & 0,25 & 0,5 & 1 & 2 & 4,7 & 6,3 \\
\hline PF & 14,79 & 14,40 & 30,20 & 23,70 & 16,68 & 0,14 & 0,09 \\
\hline PG & 11,68 & 10,86 & 22,44 & 19,54 & 31,76 & 2,58 & 1,15 \\
\hline$C F-G$ & 11,68 & 19,10 & 37,61 & 24,3 & 5,43 & 0,31 & 0,72 \\
\hline$C F-F$ & 0,00 & 0,03 & 0,31 & 0,77 & 0,00 & 0,00 & 0,00 \\
\hline$C G-G$ & 6,73 & 9,32 & 15,82 & 11,63 & 0,00 & 0,00 & 0,00 \\
\hline$C G-F$ & 2,69 & 3,11 & 8,24 & 4,41 & 5,61 & 0,00 & 32,46 \\
\hline
\end{tabular}


(a)
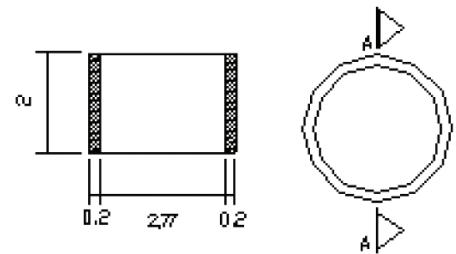

(b)

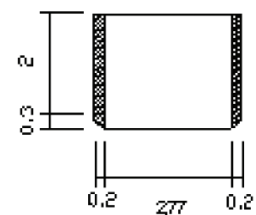

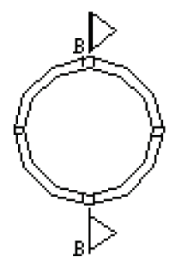

(c)

(d)

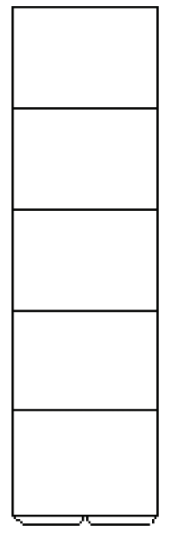

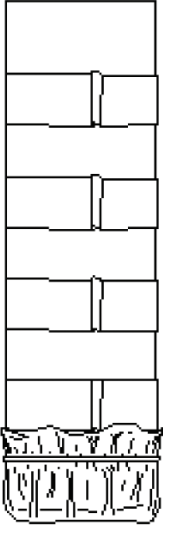

Figura 1. Esquema da coluna desmontável, detalhando um anel intermediário (a), do primeiro anel com 3 mm de altura a mais e fundo em bisel (b), cilindros empilhados (c) e a montagem de cilindros (d).

evitar a perda de material. A ligação dos anéis foi realizada por meio de fitas adesivas de PVC, conforme esquema também apresentado na figura 1 , juntamente com outros componentes descritos acima.

No preenchimento dos cilindros com substrato, foi utilizado o método proposto por Pire e Pereira (2003) e YeAger (1995), que utilizaram o diâmetro do contêiner como dimensão diretamente proporcional ao impacto de um volume de madeira com dimensôes $15 \times 10 \times 30 \mathrm{~cm}$ apoiado sobre uma mesa, buscando reduzir os erros de manuseio do substrato durante o preenchimento. Dessa forma, para substrato seco ao ar utilizaram-se dois impactos, e para o substrato úmido, foram necessários quatro impactos para o recipiente ficar totalmente cheio.

O ensaio foi realizado sobre bancada no Laboratório de Hidráulica e Irrigação da Faculdade de Engenharia Agrícola da UNICAMP, sob condiçôes atmosféricas reinantes não monitoradas em 2005 e janeiro de 2006. A saturaçáo dos substratos, a partir do anel inferior, foi realizada por contato do material com um espelho de água de $3 \mathrm{~mm}$ de espessura, formando assim uma camada saturada de $3 \mathrm{~mm}$ de altura na base dos cilindros. No início do processo de saturaçáo dos substratos, ocorreu expansão de seu volume com o aumento da umidade, principalmente nos substratos secos ao ar. Esse comportamento impossibilitou o cálculo de densidade do substrato no momento em que o cilindro foi colocado em contato com a água e do valor da umidade com base em volume para o momento em que o tempo de saturação era igual a zero minutos.

Como o valor da umidade inicial, foi determinada a umidade (\%) do substrato antes do preenchimento dos cilindros multiplicada pelo valor médio da densidade. Este último parâmetro foi obtido após a retirada dos substratos dos anéis, sua secagem e divisão do valor do peso pelo

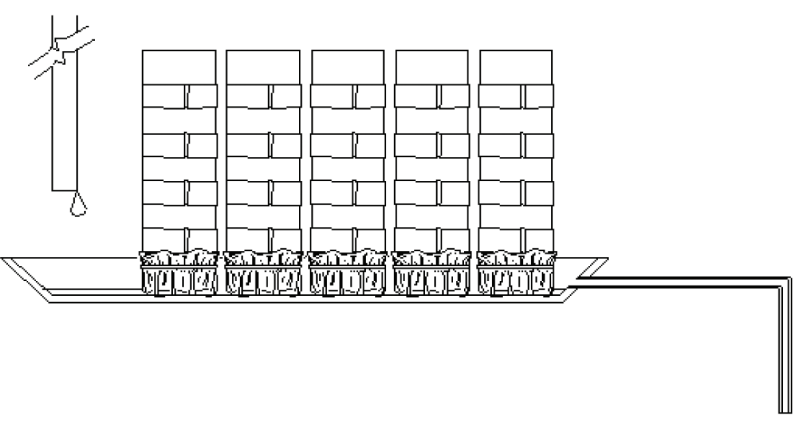

Figura 2. Esquema do sistema de saturação dos cilindros com substrato.

volume do anel. Pela figura 2, pode-se verificar o esquema do sistema de saturação das amostras, onde os cilindros com os substratos eram saturados em um recipiente que possuía uma alimentação, na qual se permite manutenção de uma lâmina constante com $3 \mathrm{~mm}$ de água, formando uma zona de saturação interna no cilindro na região de contato com a água.

Para determinação do movimento ascendente da água por capilaridade, estimaram-se, gravimetricamente, os valores da umidade de cada amostra segmentada de substrato, base massa seca, nos seguintes tempos de saturação dos substratos: 15 minutos, 30 minutos, e 1, $2,4,8,16$ e 24 horas. A cada intervalo de tempo de saturação, o cilindro era desmontado e o substrato em seu interior era inteiramente retirado para avaliação. Os volumes de substratos eram, então, secos em cadinhos de papel alumínio durante 24 horas a $65^{\circ} \mathrm{C}$ e, em seguida, pesados novamente. Determinou-se $\theta$ (umidade volumétrica) com os valores de umidade (\%) e densidade dos substratos. Foram realizadas 10 repetiçóes para cada tempo de saturaçáo e tratamento testado, utilizando o delineamento estatístico de amostras inteiramente 
casualizadas, com a aplicação do teste de Scott-Knott $(\mathrm{p}<0,05)$ a partir do programa Sisvar.

A taxa de ascensão capilar foi calculada com base nos valores totais de água armazenada na coluna, somando-se os conteúdos de umidade de cada anel. Assim, os valores foram calculados usando a diferença entre a umidade anterior e a presente no momento de sua medição de cada anel. $\mathrm{O}$ volume de água adsorvido entre a leitura anterior e a leitura presente foi dividido pelo valor em horas do intervalo de tempo entre as leituras, gerando a taxa de ascensão capilar de água em volume por hora.

\section{RESULTADOS E DISCUSSÃO}

\section{Substrato de pinus com granulometria fina}

Foi notado que a ascensão capilar ocorreu desde os primeiros instantes em que houve contato do cilindro com a água, conforme se observa na tabela $2 . \mathrm{Na}$ avaliação de 16 horas, o molhamento do anel a $9 \mathrm{~cm}$ de altura foi medido em nível estatisticamente sensível, representando apenas $31 \%$ dos anéis a $1 \mathrm{~cm}$ de altura. No entanto, nos dois anéis superiores é notada a tendência de equalização do nível de umidade com os anéis abaixo.

No substrato fino de pinus seco ao ar não houve hidrofobia, e dado que a frente de molhamento capilar atingiu o topo do cilindro antes das 24 horas, revelou-se ausência de dificuldades de molhamento. A diferença de umidade entre os anéis da base e do topo do cilindro é comum a todo substrato em contêineres pelo fato de na parte inferior dos substratos notarem-se níveis de saturação similares aos de lençóis freáticos (Nelson, 2003). Embora durante todo o período estudado houvesse estratificação da umidade no cilindro, o aumento de seus valores foi constante para todas as alturas. Por estes motivos, pode-se considerar que o substrato possui condiçốes de ascensão capilar adequada e segura para manejo da irrigação por capilaridade.

A frente de umedecimento atingiu rapidamente as diferentes alturas da coluna de substrato fino de pinus umedecido, no entanto, até 8 horas após o início da saturação, a frente de umedecimento ficou praticamente restrita até a altura de $7 \mathrm{~cm}$, de acordo com o que está mostrado na tabela 3. Entre 8 e 16 horas de teste é possível verificar que a presença da frente de molhamento atingiu o último anel a $9 \mathrm{~cm}$ de altura. Nos primeiros 15 minutos, a umidade a 1 $\mathrm{cm}$ de altura era $111,5 \%$ maior que a $9 \mathrm{~cm}$ de altura, onde a umidade não havia ainda se modificado. Esta condiçấo foi mantida até 8 horas de teste, com pequenas variaçōes. Até este tempo de teste, a frente de molhamento capilar aumentou a umidade até $7 \mathrm{~cm}$ de altura, sem, no entanto causar mudanças no anel superior. Comparativamente ao anel do topo $(9 \mathrm{~cm}$ de altura), a umidade no anel a $1 \mathrm{~cm}$ de altura foi $133,3 \%$ maior. De forma geral, os aumentos de umidade foram mais relevantes nos anéis a 1 e $3 \mathrm{~cm}$ de altura. $\mathrm{O}$ incremento de umidade nos anéis de 3 e $5 \mathrm{~cm}$ nos primeiros 15 minutos revela uma condição diferente de capacidade de transmissão de água por capilaridade entre substratos secos e umedecidos com granulometria fina. Este resultado é similar ao comportamento observado em

Tabela 2. Valores de umidade $\left(\mathrm{cm}^{3} \mathrm{~cm}^{-3}\right)$ com níveis de significância estatística de acordo com a posição vertical no durante o tempo de teste para o substrato fino de pinus sob condiçôes de umidade seco ao ar

\begin{tabular}{lccccccccc}
$\begin{array}{l}\text { Altura da } \\
\text { coluna } \\
(\mathbf{c m})\end{array}$ & $\mathbf{1 5}$ & $\mathbf{3 0}$ & $\mathbf{1}$ & $\mathbf{2}$ & $\mathbf{4}$ & $\mathbf{8}$ & $\mathbf{1 6}$ & $\mathbf{2 4}$ \\
\hline 9 & $\mathbf{( m i n )}$ & $\mathbf{( m i n )}$ & (hora) & (horas) & (horas) & (horas) & (horas) & (horas) \\
\hline 7 & $0,03 \mathrm{~g}$ & $0,03 \mathrm{~g}$ & $0,03 \mathrm{~g}$ & $0,03 \mathrm{~g}$ & $0,03 \mathrm{~g}$ & $0,04 \mathrm{~g}$ & $0,23 \mathrm{f}$ & $0,32 \mathrm{e}$ \\
\hline 5 & $0,03 \mathrm{~g}$ & $0,03 \mathrm{~g}$ & $0,03 \mathrm{~g}$ & $0,03 \mathrm{~g}$ & $0,19 \mathrm{f}$ & $0,26 \mathrm{e}$ & $0,42 \mathrm{~d}$ & $0,46 \mathrm{c}$ \\
\hline 3 & $0,03 \mathrm{~g}$ & $0,03 \mathrm{~g}$ & $0,06 \mathrm{~g}$ & $0,28 \mathrm{e}$ & $0,40 \mathrm{~d}$ & $0,41 \mathrm{~d}$ & $0,47 \mathrm{c}$ & $0,52 \mathrm{c}$ \\
\hline 1 & $0,04 \mathrm{~g}$ & $0,33 \mathrm{e}$ & $0,50 \mathrm{c}$ & $0,62 \mathrm{~b}$ & $0,62 \mathrm{~b}$ & $0,63 \mathrm{~b}$ & $0,70 \mathrm{a}$ & $0,68 \mathrm{a}$ \\
\hline
\end{tabular}

Médias seguidas da mesma letra, em qualquer posição do gráfico, não diferem entre si para alturas da coluna, pelo teste de Scott-Knott (p>0,05).

Tabela 3. Valores de umidade $\left(\mathrm{cm}^{3} \mathrm{~cm}^{-3}\right)$ com níveis de significância estatística de acordo com a posição vertical durante o tempo de teste para o substrato fino de pinus sob condiçôes de umidade de comercialização

\begin{tabular}{|c|c|c|c|c|c|c|c|c|}
\hline \multirow{3}{*}{$\begin{array}{l}\text { Altura da } \\
\text { coluna }(\mathrm{cm})\end{array}$} & \multicolumn{8}{|c|}{ Tempo de saturação } \\
\hline & 15 & 30 & 1 & 2 & 4 & 8 & 16 & 24 \\
\hline & $(\min )$ & (min) & (hora) & (horas) & (horas) & (horas) & (horas) & (horas) \\
\hline 9 & $0,26 \mathrm{~m}$ & $0,25 \mathrm{~m}$ & $0,26 \mathrm{~m}$ & $0,26 \mathrm{~m}$ & $0,27 \mathrm{~m}$ & $0,27 \mathrm{~m}$ & 0,301 & 0,301 \\
\hline 7 & 0,291 & $0,26 \mathrm{~m}$ & 0,291 & $0,34 \mathrm{k}$ & $0,34 k$ & $0,34 k$ & $0,35 j$ & $0,34 \mathrm{k}$ \\
\hline 5 & 0,311 & $0,33 \mathrm{k}$ & $0,34 j$ & $0,37 \mathrm{j}$ & $0,39 \mathrm{i}$ & $0,38 \mathrm{i}$ & $0,42 \mathrm{~h}$ & $0,39 \mathrm{i}$ \\
\hline 3 & $0,42 \mathrm{~h}$ & $0,43 \mathrm{~h}$ & $0,45 \mathrm{~g}$ & $0,45 \mathrm{~g}$ & $0,49 \mathrm{f}$ & $0,47 \mathrm{~g}$ & $0,49 f$ & $0,46 \mathrm{~g}$ \\
\hline 1 & 0,55 e & $0,57 \mathrm{~d}$ & $0,59 \mathrm{c}$ & $0,62 \mathrm{~b}$ & $0,65 a$ & $0,63 b$ & $0,65 \mathrm{a}$ & $0,65 \mathrm{a}$ \\
\hline
\end{tabular}

Médias seguidas da mesma letra, em qualquer posição do gráfico, nẫo diferem entre si para alturas da coluna, pelo teste de Scott-Knott ( $\mathrm{p}>0,05)$. 
solos, onde a condutividade hidráulica é maior no substrato umedecido do que para o meio seco (CARON e ElRICK, 2005). O anel superior aumentou pouco sua umidade devido, provavelmente, ao efeito da demanda atmosférica que aumentou o fluxo de vapor da água no anel superior.

\section{Substrato de pinus com granulometria grosseira}

Para o substrato grosseiro de pinus seco ao ar, a frente de molhamento atingiu sensivelmente o anel a $5 \mathrm{~cm}$ de altura em 2 horas de saturaçáo, evento demonstrado na tabela 4. Com 16 horas de experimento, a frente de molhamento capilar alcançou o anel superior do cilindro, com a umidade nesse anel representando $45 \%$ da quantidade de água armazenada a $1 \mathrm{~cm}$ de altura. Às 24 horas de ensaio houve aumento relevante da umidade a $9 \mathrm{~cm}$ de altura, acarretando maior uniformidade no perfil, o que não foi observado no substrato fino de pinus em ambas as condiçóes de umidade. Tal efeito pode ser atribuído à reduzida fração de partículas finas, responsável por ascender mais água nos anéis próximos à água, elevando a umidade a valores próximos à saturação. A natureza grosseira do substrato atribuiu menor capacidade de armazenamento de água no meio, quando comparados com o substrato de granulometria fina.

No substrato grosseiro de pinus seco ao ar não foram observados sinais de hidrofobia, principalmente, quando se constatou que a frente de umedecimento capilar atingiu o topo do cilindro antes das 24 horas de ensaio, revelando boa capacidade de molhamento ao longo do cilindro. A granulometria grosseira do substrato de pinus não impediu o processo de ascensão capilar, no entanto, comparativamente com o substrato fino (Tabela 2) houve menor volume de água ascendido. Embora esse substrato tenha atingido condiçóes suficientes para promover a irrigação por capilaridade, nota-se que baixos valores de umidade podem ocorrer, comprometendo a eficiência de molhamento do perfil.

Foi notado que no substrato grosseiro de pinus umedecido, a frente de molhamento capilar foi mais lenta que os outros tratamentos, e o umedecimento náo foi efetivo em toda a coluna de substrato, conforme se observa na tabela 5 .

$\mathrm{Na}$ camada superior, a $9 \mathrm{~cm}$ de altura, houve redução na quantidade de água, provavelmente devido ao efeito da evaporação atmosférica. $\mathrm{O}$ fraco molhamento capilar aliado com a reduçáo do nível de umidade das camadas superiores remete ao fato que o substrato grosseiro de pinus não tem propriedades físicas capazes de conduzir água por uma coluna de substrato de $10 \mathrm{~cm}$ de altura. Neste substrato úmido notou-se menor quantidade de água elevada pela coluna e menor altura de ascensão de água quando comparado com o substrato fino umedecido.

De forma geral, os substratos de pinus secos não hidrofóbicos possuem maior gradiente de potencial hídrico em relação às zonas saturadas, traduzindo em maior volume de água adsorvido, sem, no entanto, transmiti-lo rapidamente para camadas superiores.

Tabela 4. Valores de umidade $\left(\mathrm{cm}^{3} \mathrm{~cm}^{-3}\right)$ com níveis de significância estatística de acordo com a posição vertical durante o tempo de teste para o substrato grosseiro de pinus seco ao ar

\begin{tabular}{|c|c|c|c|c|c|c|c|c|}
\hline \multirow{3}{*}{ Altura da coluna $(\mathrm{cm})$} & \multicolumn{8}{|c|}{ Tempo de saturação } \\
\hline & 15 & 30 & 1 & 2 & 4 & 8 & 16 & 24 \\
\hline & $(\min )$ & $(\min )$ & (hora) & (horas) & (horas) & (horas) & (horas) & (horas) \\
\hline 9 & $0,03 \mathrm{~h}$ & $0,03 \mathrm{~h}$ & $0,03 \mathrm{~h}$ & $0,03 \mathrm{~h}$ & $0,04 \mathrm{~h}$ & $0,04 \mathrm{~h}$ & $0,27 \mathrm{f}$ & $0,40 \mathrm{c}$ \\
\hline 7 & $0,03 \mathrm{~h}$ & $0,03 \mathrm{~h}$ & $0,03 \mathrm{~h}$ & $0,03 \mathrm{~h}$ & $0,17 \mathrm{~g}$ & $0,19 \mathrm{~g}$ & $0,34 \mathrm{~d}$ & $0,38 c$ \\
\hline 5 & $0,03 \mathrm{~h}$ & $0,03 \mathrm{~h}$ & $0,09 \mathrm{~h}$ & $0,20 \mathrm{~g}$ & $0,34 \mathrm{~d}$ & 0,28 e & $0,40 c$ & $0,44 c$ \\
\hline 3 & $0,05 \mathrm{~h}$ & $0,17 \mathrm{~g}$ & $0,37 c$ & $0,39 c$ & $0,44 c$ & $0,40 c$ & $0,48 b$ & $0,52 b$ \\
\hline 1 & $0,53 b$ & $0,55 b$ & $0,51 \mathrm{~b}$ & $0,61 \mathrm{a}$ & $0,59 a$ & $0,54 b$ & $0,60 \mathrm{a}$ & $0,64 \mathrm{a}$ \\
\hline
\end{tabular}

Médias seguidas da mesma letra, em qualquer posiçăo do gráfico, não diferem entre si para alturas da coluna, pelo teste de $S$ cott-Knott ( $\mathrm{p}>0,05)$.

Tabela 5. Valores de umidade $\left(\mathrm{cm}^{3} \mathrm{~cm}^{-3}\right)$ com níveis de significância estatística de acordo com a posição vertical durante o tempo de teste para o substrato de pinus grosseiro umedecido comercialmente

\begin{tabular}{|c|c|c|c|c|c|c|c|c|}
\hline \multirow{3}{*}{$\begin{array}{l}\text { Altura da } \\
\text { coluna }(\mathrm{cm})\end{array}$} & \multicolumn{8}{|c|}{ Tempo de saturação } \\
\hline & 15 & 30 & 1 & 2 & 4 & 8 & 16 & 24 \\
\hline & (min) & $(\min )$ & (hora) & (horas) & (horas) & (horas) & (horas) & (horas) \\
\hline 9 & $0,27 k$ & $0,27 k$ & $0,27 k$ & $0,26 k$ & 0,251 & 0,241 & $0,22 \mathrm{~m}$ & $0,23 \mathrm{~m}$ \\
\hline 7 & $0,27 k$ & $0,27 k$ & $0,27 k$ & $0,27 k$ & $0,29 j$ & $0,30 \mathrm{i}$ & $0,29 \mathrm{j}$ & $0,31 \mathrm{i}$ \\
\hline 5 & $0,27 \mathrm{k}$ & $0,29 j$ & $0,28 j$ & $0,29 j$ & $0,32 \mathrm{~h}$ & $0,35 \mathrm{~g}$ & $0,32 \mathrm{~h}$ & $0,34 \mathrm{~g}$ \\
\hline 3 & $0,28 \mathrm{j}$ & $0,30 \mathrm{i}$ & $0,34 \mathrm{~g}$ & $0,35 \mathrm{~g}$ & $0,38 \mathrm{f}$ & 0,39 e & $0,35 \mathrm{~g}$ & 0,39 e \\
\hline 1 & $0,37 \mathrm{f}$ & $0,40 \mathrm{e}$ & $0,48 c$ & $0,44 \mathrm{~d}$ & $0,50 \mathrm{~b}$ & $0,52 a$ & $0,50 \mathrm{~b}$ & $0,49 \mathrm{~b}$ \\
\hline
\end{tabular}

Médias seguidas da mesma letra, em qualquer posição do gráfico, não diferem entre si para alturas da coluna, pelo teste de Scott-Knott ( $p>0,05)$. 


\section{Substrato de coco com granulometria fina}

Comparativamente ao substrato fino de pinus seco ao ar, no substrato de coco havia menor umidade ao longo do seu perfil nessa mesma condição de granulometria, conforme se nota na tabela 6 . A quantidade de água armazenada nessa condiçấo de substrato foi de $0,01 \mathrm{~cm}^{3} \mathrm{~cm}^{-3}$, enquanto para o substrato de pinus foi de $0,03 \mathrm{~cm}^{3} \mathrm{~cm}^{-3}$. Esse comportamento pode ser explicado pela condição hidrofóbica atingida pela fibra de coco após a exposição ao poder dessecante da atmosfera.

O comportamento do substrato de coco na condiçáo de seco ao ar dificulta seu uso para condiçóes de manejo hídrico com baixa frequência de irrigação, pela possibilidade de ocorrer um secamento desse meio de crescimento. $\mathrm{O}$ uso deste substrato na irrigação por capilaridade implica risco para o sistema de produção, tornando-o suscetível a quebras ou reduçáo de produtividade devido à baixa uniformidade de distribuição de água.

Essa característica hidrofóbica da fibra de coco nessa condiçáo de umidade pode ser explicada pela presença de tanino em sua composiçáa. Apesar de haver, no processo industrial para produção de substrato de fibra de coco, uma etapa obrigatória de lavagem das fibras para remoção de tanino e outras substâncias (CARRIJo et al., 2002), Brígida e Rosa (2003), afirmam que no pericarpo de coco verde a porcentagem de tanino pode chegar a de $6,0 \%$ do peso total, e que em condição de baixa umidade, a presença residual de tanino pode tornar-se significativa. Isso se deve ao fato de que os taninos possuem natureza hidrofóbica, e se adsorvem até em resinas sem carga
(Он et al., 1980) e esta substância pode ser encontrada em matéria orgânica vegetal, tais como aquelas derivadas de pinus (Suominen et al., 2003). Embora esta substância seja solúvel, a baixa quantidade de água pode gerar uma solução com alta concentração devido ao reduzido volume de água de constituição residual nas partículas. Contrariamente, quando esse substrato está úmido, os resíduos de tanino podem se tornar insignificantes em seus efeitos reduzidos devido à grande diluição. No entanto, mesmo em condições de predominância de partículas finas no substrato de coco, fator que Michel et al. (2008) preconizam para ocorrer facilidade de molhamento, a hidrofobia quando presente é uma condição que pode ser definida como fator dominante no processo.

É possível verificar que houve rápido molhamento do perfil no processo de umedecimento, representado na tabela 7. Aos 30 minutos de teste, ocorreu aumento na umidade com a frente de molhamento atingindo o topo do cilindro. A umidade na camada de $1 \mathrm{~cm}$ foi $117 \%$ maior do que a observada nas camadas de 7 e $9 \mathrm{~cm}$ de altura.

Esse substrato pode transmitir água para camadas superiores via capilaridade, porém, sujeito à dessecação atmosférica.

\section{Substrato de coco com granulometria grosseira}

No substrato de coco grosseiro seco ao ar não se verificou ascensão de água ao longo da coluna. Este comportamento é o mesmo observado para o substrato fino de

Tabela 6. Valores de umidade $\left(\mathrm{cm}^{3} \mathrm{~cm}^{-3}\right)$ com níveis de significância estatística de acordo com a posição vertical durante o tempo de teste para o substrato fino de coco seco ao ar

\begin{tabular}{|c|c|c|c|c|c|c|c|c|}
\hline \multirow{3}{*}{$\begin{array}{l}\text { Altura da } \\
\text { coluna }(\mathrm{cm})\end{array}$} & \multicolumn{8}{|c|}{ Tempo de saturação } \\
\hline & 15 & 30 & 1 & 2 & 4 & 8 & 16 & 24 \\
\hline & (min) & (min) & (hora) & (horas) & (horas) & (horas) & (horas) & (horas) \\
\hline 9 & 0,01 e & 0,01 e & 0,01 e & 0,01 e & 0,01 e & 0,01 e & 0,01 e & 0,01 e \\
\hline 7 & 0,01 e & $0,01 \mathrm{e}$ & $0,01 \mathrm{e}$ & 0,01 e & 0,01 e & 0,01 e & 0,01 e & $0,01 \mathrm{e}$ \\
\hline 5 & 0,01 e & $0,01 \mathrm{e}$ & 0,01 e & 0,01 e & 0,01 e & 0,01 e & 0,01 e & 0,01 e \\
\hline 3 & 0,01 e & 0,01 e & 0,01 e & 0,01 e & 0,01 e & 0,01 e & 0,01 e & 0,01 e \\
\hline 1 & $0,01 \mathrm{e}$ & $0,01 \mathrm{e}$ & $0,01 \mathrm{e}$ & $0,01 \mathrm{e}$ & $0,04 \mathrm{~d}$ & $0,07 \mathrm{c}$ & $0,15 \mathrm{~b}$ & $0,26 a$ \\
\hline
\end{tabular}

Médias seguidas da mesma letra, em qualquer posição do gráfico, nâo diferem entre si para alturas da coluna, pelo teste de Scott-Knott (p>0,05).

Tabela 7. Valores de umidade $\left(\mathrm{cm}^{3} \mathrm{~cm}^{-3}\right)$ com níveis de significância estatística de acordo com a posição vertical durante o tempo de teste para o substrato fino de coco com umidade comercial

\begin{tabular}{|c|c|c|c|c|c|c|c|c|}
\hline \multirow{3}{*}{$\begin{array}{l}\text { Altura da } \\
\text { coluna }(\mathrm{cm})\end{array}$} & \multicolumn{8}{|c|}{ Tempo de saturação } \\
\hline & 15 & 30 & 1 & 2 & 4 & 8 & 16 & 24 \\
\hline & (min) & (min) & (hora) & (horas) & (horas) & (horas) & (horas) & (horas) \\
\hline 9 & 0,261 & $0,29 k$ & $0,29 \mathrm{k}$ & $0,30 \mathrm{j}$ & 0,27 I & $0,28 \mathrm{k}$ & $0,31 \mathrm{j}$ & 0,261 \\
\hline 7 & 0,271 & $0,29 k$ & $0,30 j$ & $0,32 i$ & $0,31 \mathrm{j}$ & $0,32 i$ & $0,33 i$ & $0,33 i$ \\
\hline 5 & $0,32 \mathrm{i}$ & $0,33 i$ & $0,35 \mathrm{i}$ & $0,38 \mathrm{~h}$ & $0,38 \mathrm{~h}$ & $0,37 \mathrm{~h}$ & $0,38 \mathrm{~h}$ & $0,38 \mathrm{~h}$ \\
\hline 3 & $0,42 \mathrm{~h}$ & $0,44 \mathrm{~g}$ & $0,43 \mathrm{~g}$ & $0,47 \mathrm{f}$ & $0,47 \mathrm{f}$ & $0,48 \mathrm{f}$ & $0,48 \mathrm{f}$ & $0,50 \mathrm{f}$ \\
\hline 1 & $0,61 \mathrm{e}$ & 0,63 e & $0,66 \mathrm{~d}$ & $0,72 b$ & $0,69 \mathrm{c}$ & $0,74 a$ & $0,69 c$ & $0,75 a$ \\
\hline
\end{tabular}

Médias seguidas da mesma letra, em qualquer posição do gráfico, nẫo diferem entre si para alturas da coluna, pelo teste de Scott-Knott ( $\mathrm{p}>0,05)$. 
coco nessa condição de umidade, mas com o agravamento do efeito gerado pela maior fração de partículas grandes presentes no substrato. Essa constituição fibrosa reduz o contato entre partículas, reduzindo a chance da ascensão capilar (Tabela 8).

No substrato grosseiro de coco umedecido comercialmente, notou-se fraco efeito de ascensão capilar, conforme se evidencia na tabela 9. A natureza do substrato aliada à baixa porcentagem de componentes finos são os fatores determinantes desse comportamento, além de reduzir o armazenamento de água ao longo da coluna. Pode-se afirmar que neste substrato não houve ascensão capilar, com presença da franja capilar no primeiro anel. Como consequência desta característica, ocorrem perdas de água na coluna. Outro fator que colabora para o comportamento deste substrato é sua excessiva aeração, causada pela quantidade de fibras grosseiras em um pequeno recipiente. Desta forma, esse substrato não pode ser empregado no uso de pequenos recipientes, pois seus componentes excessivamente alongados formam estruturas de aeração que atribuem a não continuidade ao meio, comprometendo a ascensão capilar.

\section{Considerações sobre os substratos estudados}

Para os substratos de pinus em ambas as condiçóes de granulometria e de umidade e para o substrato de coco fino na condição umedecida notou-se que o aumento de umidade na camada a $1 \mathrm{~cm}$ atingiu valores próximos à capacidade do contêiner logo após seu contato com a água, enquanto nas camadas superiores houve continuidade no aumento da umidade. $\mathrm{O}$ comportamento observado para a primeira camada é devido à franja capilar, que permitiu o rápido molhamento com redução do gradiente de energia potencial entre as partículas e a água. Simultaneamente à redução do gradiente de potencial matricial na primeira camada, a afinidade por água por camadas superiores tornou-se um fator para continuidade na ascensão de água para regióes superiores com menor umidade, porém de forma mais pronunciada no substrato seco. A ascensão de água dá-se por força de energias matriciais eletronegativas do substrato e em contraposição ao potencial gravitacional, (LiBARDI, 2005). A energia gravitacional é responsável pelo maior armazenamento de água no fundo do recipiente, independentemente da capacidade de ascensão capilar do meio de crescimento de raízes.

Foi observado que os substratos de pinus em textura fina e grosseira foram aqueles que melhor adsorveram água, fenômeno identificado na figura 3 . As taxas de ascensão de água na coluna de substrato fino de pinus secos ao ar foram para 15 minutos, 30 minutos, 1 hora, 2 horas, 4 horas, 8 horas, 16 horas e 24 horas, respectivamente, 27,$6 ; 16,1 ; 5,2 ; 5,2 ; 1,7 ; 0,3 ; 0,7 \mathrm{e}$ $0,2 \mathrm{~cm}^{3} \mathrm{~h}^{-1}$. Para o substrato grosseiro de pinus essas taxas ao longo do tempo foram de 25,$2 ; 6,3 ; 5,3 ; 2,9$; 1,$9 ;-0,4 ; 1,0 ; 0,5 \mathrm{~cm}^{3} \mathrm{~h}^{-1}$. Estes substratos mantiveram por maior tempo do experimento as maiores taxas de ascensão de água por capilaridade. Este comportamento pode ser atribuído à diferença de potencial ser maior

Tabela 8. Valores de umidade $\left(\mathrm{cm}^{3} \mathrm{~cm}^{-3}\right)$ com níveis de significância estatística de acordo com a posição vertical durante o tempo de teste para o substrato grosseiro de coco seco ao ar

\begin{tabular}{|c|c|c|c|c|c|c|c|c|}
\hline \multirow{3}{*}{$\begin{array}{l}\text { Altura da } \\
\text { coluna }(\mathrm{cm})\end{array}$} & \multicolumn{8}{|c|}{ Tempo de saturação } \\
\hline & 15 & 30 & 1 & 2 & 4 & 8 & 16 & 24 \\
\hline & (min) & (min) & (hora) & (horas) & (horas) & (horas) & (horas) & (horas) \\
\hline 9 & $0,01 \mathrm{e}$ & $0,01 \mathrm{e}$ & 0,01 e & 0,01 e & 0,01 e & 0,01 e & 0,01 e & 0,01 e \\
\hline 7 & $0,01 \mathrm{e}$ & $0,01 \mathrm{e}$ & $0,01 \mathrm{e}$ & 0,01 e & 0,01 e & 0,01 e & 0,01 e & 0,01 e \\
\hline 5 & $0,01 \mathrm{e}$ & $0,01 \mathrm{e}$ & 0,01 e & 0,01 e & 0,01 e & 0,01 e & 0,01 e & 0,01 e \\
\hline 3 & $0,01 \mathrm{e}$ & 0,01 e & 0,01 e & 0,01 e & 0,01 e & 0,01 e & 0,01 e & 0,01 e \\
\hline 1 & $0,01 \mathrm{e}$ & $0,01 \mathrm{e}$ & $0,01 \mathrm{e}$ & $0,01 \mathrm{e}$ & $0,02 \mathrm{~d}$ & 0,022 c & $0,025 \mathrm{~b}$ & $0,03 a$ \\
\hline
\end{tabular}

Médias seguidas da mesma letra, em qualquer posição do gráfico, não diferem entre si para alturas da coluna, pelo teste de Scott-Knott ( $\mathrm{p}>0,05)$.

Tabela 9. Valores de umidade $\left(\mathrm{cm}^{3} \mathrm{~cm}^{-3}\right)$ com níveis de significância estatística de acordo com a posição vertical durante o tempo de teste para o substrato de fibra de coco umedecido

\begin{tabular}{|c|c|c|c|c|c|c|c|c|}
\hline \multirow{3}{*}{$\begin{array}{l}\text { Altura da } \\
\text { coluna }(\mathrm{cm})\end{array}$} & \multicolumn{8}{|c|}{ Tempo de saturação } \\
\hline & 15 & 30 & 1 & 2 & 4 & 8 & 16 & 24 \\
\hline & $(\mathrm{min})$ & $(\min )$ & (hora) & (horas) & (horas) & (horas) & (horas) & (horas) \\
\hline 9 & $0,06 \mathrm{c}$ & $0,06 \mathrm{c}$ & $0,04 d$ & $0,04 \mathrm{~d}$ & $0,01 \mathrm{f}$ & $0,01 \mathrm{f}$ & $0,01 \mathrm{f}$ & $0,01 \mathrm{f}$ \\
\hline 7 & $0,06 \mathrm{c}$ & $0,06 \mathrm{c}$ & $0,05 d$ & $0,06 \mathrm{c}$ & 0,03 e & $0,04 d$ & $0,02 \mathrm{f}$ & $0,01 \mathrm{f}$ \\
\hline 5 & $0,06 c$ & $0,07 \mathrm{c}$ & $0,05 d$ & $0,07 \mathrm{c}$ & $0,04 \mathrm{~d}$ & $0,04 \mathrm{~d}$ & 0,03 e & $0,04 \mathrm{~d}$ \\
\hline 3 & $0,06 c$ & $0,07 c$ & $0,06 c$ & $0,08 \mathrm{c}$ & $0,05 d$ & $0,05 d$ & $0,05 d$ & $0,06 \mathrm{c}$ \\
\hline 1 & $0,11 b$ & $0,09 \mathrm{~b}$ & $0,10 \mathrm{~b}$ & $0,15 a$ & $0,12 \mathrm{~b}$ & $0,11 b$ & 0,12 b & $0,12 b$ \\
\hline
\end{tabular}

Médias seguidas da mesma letra, em qualquer posição do gráfico, năo diferem entre si para alturas da coluna, pelo teste de Scott-Knott ( $>>0,05)$. 


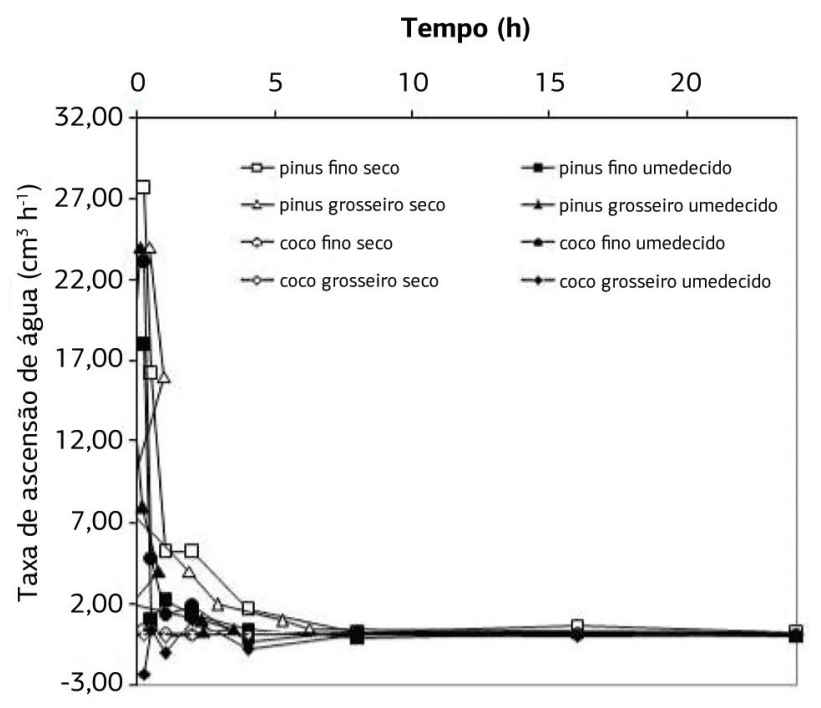

Figura 3. Variação da taxa de ascensão de água para as colunas de substratos durante as 24 horas de ensaio

entre a zona saturada e a coluna de substrato seca e não hidrofóbica. O substrato fino de coco, hidrofóbico quando seco ao ar, possui ótima capacidade de ascensão de água por capilaridade. Este substrato proporcionou a melhor taxa de ascensão de substratos molhados devido às suas propriedades matriciais. As taxas de ascensão para o substrato fino de coco molhado são de 23,1; 4,$7 ; 1,3 ; 1,8 ;-0,4 ; 0,2 ; 0$ e $0 \mathrm{~cm}^{3} \mathrm{~h}^{-1}$. Para o mesmo período estudado, no substrato fino de pinus molhado os valores foram os seguintes: 17,$9 ; 1,0 ; 2,2 ; 1,3 ; 0,5$; $-0,1 ; 0,2$ e $-0,1 \mathrm{~cm}^{3} \mathrm{~h}^{-1}$.

Apresentando baixas taxas de ascensão de água, observaram-se perdas de água nos substratos grosseiros de coco e de pinus. No primeiro, quando seco, ocorre hidrofobia, da mesma forma que no substrato fino também de coco. Mas, ao contrário do substrato fino de coco, o substrato grosseiro molhado possui ascensão capilar nula e perdas de água, traduzindo em taxas negativas. As taxas de ascensão acumuladas para o substrato grosseiro de coco molhado foram: $-2,3 ; 0,4 ;-1,1 ; 1,1$; $-0,8 ; 0 ;-0,1$ e $0 \mathrm{~cm}^{3} \mathrm{~h}^{-1}$. Esse comportamento ocorre pelo excesso de fibras grosseira, que formam estruturas abertas as quais atribuem náo continuidade ao meio, comprometendo o contato entre partículas, essencial à ascensão capilar de água. No substrato grosseiro de pinus molhado as taxas de ascensão capilar foram intermediárias para o período estudado, ou seja, de 2,4; 3,$5 ; 2,4 ;-0,2 ; 0,8 ; 0,2 ;-0,2$ e $0,1 \mathrm{~cm}^{3} \mathrm{~h}^{-1}$. A variação das condiçóes atmosféricas no momento dos ensaios, aliada à variação das propriedades físicas dos substratos podem ser responsáveis pela oscilaçáo com valores negativos. Essa hipótese é válida tanto para as variaçôes ocorridas no substrato fino de coco umedecido como para o substrato grosseiro de pinus umedecido.

\section{CONCLUSÃO}

O substrato fino de pinus é adequado para a irrigação por capilaridade em tubetes, pois possibilita o molhamento do meio com baixo contato da lâmina de água. $\mathrm{O}$ mesmo substrato em textura grosseira é inadequado para irrigação em tubetes de $50 \mathrm{~cm}^{3}$, pois demanda maior elevação da lâmina de água para vencer o ressecamento atmosférico.

O substrato fino de coco é adequado para a irrigação por capilaridade em tubetes de $50 \mathrm{~cm}^{3}$ por empregar mínima elevação de água no perfil. O manejo hídrico desse substrato deve ser criterioso, pois umedecimentos excessivos podem acarretar problemas por excesso de umidade devido à sua capacidade de retenção, e por outro lado, a deficiência de umidade nas camadas superiores do substrato pode acarretar em hidrofobia. O substrato grosseiro de coco não deve ser empregado sob nenhuma condiçấo para irrigação por capilaridade em pequenos recipientes.

\section{AGRADECIMENTOS}

Os autores agradecem ao Conselho Nacional de Desenvolvimento Científico e Tecnológico (CNPq) e pelo apoio financeiro e às empresas MecPlant e Amafibra - Fibras e Substratos Agrícolas da Amazônia Ltda., pelo fornecimento dos substratos testados.

\section{REFERÊNCIAS}

BACHMANN, J.; HORTON, R.; VAN DER PLOEG, R.R.; WOCHEA, S. Modified sessile drop method for assessing initial soil-water contact angle of sandy soil. Soil Science Society of America Journal, v.64, p.564-567, 2000.

BERKOWITZ, B.; SILLIMAN, S.E.; DUNN, A.M. Impact of the capillary fringe on local flow, chemical migration and microbiology. Vadose Zone Journal, v.3, p.534-548, 2004.

BILDERBACK, T.E. Environmentally compatible container plant production practices. Acta Horticulturae, n.548, p.311-317, 2001.

BLOK, C; WEVER, G. Experience with selected physical methods to characterize the suitability of growing media or plant growth. Acta Horticulturae, n.779, p. 239-248, 2008.

BRÍGIDA, A.I.S.; ROSA, M.F. Determinação do teor taninos na casca de coco verde (Cocos nucifera). Proceedings of the Interamerican Society for Tropical Horticulture, v.47, p.25-27, 2003.

CARON, J.; ELRICK D.E. Measuring the unsaturated hydraulic conductivity of growing media with a tension disc. Soil Science Society American Journal, v.69, p.783-793, 2005.

CARON, J.; ELRICK, D.E. Defining critical capillary rise properties for growing media: Model and methodology. Acta Horticulturae, n.779, p.149-153, 2008. 
CARON, J.; ELRICK, D.E.; BEESON, R.; BOUDREAU, J. Defining critical capillary rise properties for growing media in nurseries. Soil Science Society American Journal, v.69, p.794-806, 2005

CARRIJO, O.A.; DE LIZ, R.S.; MAKISHIMA, N. Fibra da casca do coco verde como substrato agrícola. Horticultura Brasileira, v. 20, p. $533-535,2002$.

CHANSEETIS, C.; SHINOHARA, Y.; TAKAGAKI, M.; MARUO, T.; HOHJO M.; ITO, T. Application of capillary hydroponic system to the lettuce growing under tropical climate conditions. Acta Horticulturae, n.548, p.401-407, 2001.

GOEBEL, M.-O.; BACHMANN, J.; WOCHE, S.K.; FISHER, W.R.; HORTON, R. Water Potential and Aggregate Size Effects on Contact Angle and surface Energy. Soil Science Society American Journal, v.68, p.383-393, 2002.

OH, H.I.; HOFF, J.E.; ARMSTRONG, G.S.; HAFF, L.A. Hydrophobic interaction in tannin-protein complexes. Journal of Agricultural and Food Chemistry, v.28, p.394-398, 1980.

KARAGUNDUZ, A.; PENNEL, K.D.; YOUNG, M.H. Influence of nonionic surfactant on the water retention properties of unsaturated soils. Soil Science Society of America Journal, v.65, p.1392-1399, 2001.

LIBARDI, P.L. Dinâmica da água no solo. São Paulo: Editora da Universidade de Sáo Paulo, 2005.335p.
MANEV, E.D.; NGUYEN, A.V. Critical thickness of microscopic thin liquid films. Advances in Colloid and Interface Science, v.114115, p.133-146, 2005.

MICHEL, J.C.; NAASZ, R.; CHARPENTIER, S.; CARON, J. Water repellency of organic growing media and its consequences on their hydraulic properties. Acta Horticulturae, n.779, p.121-129, 2008.

NELSON, P.V. Greenhouse operation \& Management. New Jersey: Upper Saddle River, 2003. 692 p.

PIRE, R.; PEREIRA, A. Propriedades físicas de componentes de sustratos de uso comúnenla horticultura del estado Lara, Venezuela: Propuesta Metodológica. Bioagro, v.15, p.55-63, 2003.

SUOMINEN, K.; KITUNEN, V.; SMOLANDER, A. Characteristics of dissolved organic matter and phenolic compounds in forest soils under silver birch (Betula pendula), Norway spruce (Picea abies) and Scots pine (Pinus sylvestris). European Journal of Soil Science, v.54, p.287-293, 2003.

TOKUNAGA, T.K.; OLSON, K.R.; WAN, J. Moisture characteristics of Hanford gravels: Bulk, grain-surface, and intragranular components. Vadoze Zone Journal, v.2, p.322-329, 2003.

TOSHIAKI, A.M.; HIGASHIURA, M.; YOKOYAMA, T.; OKUBO, H.; NAKAGAWA, H.; KAJIHARA, A. Spatial distribution of ions in groundwater under agricultural land. Journal of Irrigation and Drainage Engineering, v.130, p.468, 2004.

YEAGER, T.H. Container Substrate Physical Properties. The Woody Ornamentalist, v.20, 1995.

\section{Errata}

\section{Pág. 388}

Tabela 2 - $2 .{ }^{\mathrm{a}}$ coluna

Onde se lê: $0,59 \mathrm{~g}$

Leia-se: $0,59 \mathrm{~b}$

Pág. 392

\section{Agradecimentos}

Onde se lê:

Os autores agradecem ao Conselho Nacional de Desenvolvimento Científico e Tecnológico (CNPq) e pelo apoio financeiro e às empresas MecPlant e Amafibra- Fibras e Substratos Agrícolas da Amazônia Ltda., pelo fornecimento dos substratos testados.

\section{Leia-se:}

Os autores agradecem ao Conselho Nacional de Desenvolvimento Científico e Tecnológico (CNPq) pelo apoio financeiro e às empresas MecPlant e Amafibra- Fibras e Substratos Agrícolas da Amazônia Ltda., pelo fornecimento dos substratos testados. 